\title{
Student pharmacist initiated medication reconciliation in the outpatient setting
}

\author{
Miranda R. ANDRUS
}

Received (first version): 24-Oct-2011

Accepted: 27-Mar-2012

\begin{abstract}
$^{*}$
The Joint Commission continues to emphasize the importance of medication reconciliation in all practice settings. Pharmacists and student pharmacists are uniquely trained in this aspect of patient care, and can assist with keeping accurate and complete medication records through patient interview in the outpatient setting.

Objective: The objective of this study was to quantify and describe medication reconciliation efforts by student pharmacists in an outpatient family medicine center.

Methods: A retrospective review was conducted of all standard medication reconciliation forms completed by student pharmacists during patient interviews from April 2010 to July 2010. The number of reviews conducted was recorded, along with the frequency of each type of discrepancy. A discrepancy was defined as any lack of agreement between the medication list in the electronic health record (EHR) and the patient-reported regimen and included any differences in dose or frequency of a medication, duplication of the same medication, medication no longer taken or omission of any medication.

Results: A total of 213 standard medication forms from the 4 month period were reviewed. A total of 555 discrepancies were found, including medications no longer taken, prescription medications that needed to be added to the EHR, over-the-counter(OTC) and herbal medications that needed to be added to the EHR, medications taken differently than recorded in the EHR, and medication allergies which needed to be updated. An average of 2.6 discrepancies was found per patient interviewed.

Conclusion: Student pharmacist-initiated medication reconciliation in an outpatient family medicine center resulted in the resolution of numerous discrepancies in the medication lists of individual patients. Pharmacists and student pharmacists are uniquely trained in medication history taking and play a vital role in medication reconciliation in the outpatient setting.
\end{abstract}

Keywords: Medication Reconciliation. Continuity of Patient Care. Electronic Health Records. Students, Pharmacy. United States.

"Miranda R. ANDRUS. PharmD, FCCP, BCPS. Associate Clinical Professor of Pharmacy Practice. Harrison School of Pharmacy, Auburn University. Huntsville, AL (United States)

\author{
RECONCILIACIÓN DE LA MEDICACIÓN \\ INICIADA POR ESTUDIANTES DE \\ FARMACIA EN AMBIENTE \\ AMBULATORIO
}

\section{RESUMEN}

La Joint Commission continúa enfatizando la importancia de la reconciliación de la medicación en todos los entornos sanitarios. Los farmacéuticos y los estudiantes de farmacia están especialmente entrenados en este aspecto de la atención al paciente y pueden ayudar manteniendo historiales de medicación precisos y completos mediante entrevista con los pacientes en el entorno ambulatorio.

Objetivo: El objetivo de este estudio fue cuantificar y describir los esfuerzos en reconciliación de la medicación por estudiantes de farmacia en un centro ambulatorio de medicina de familia.

Métodos: Se realizó una revisión retrospectiva de todos los formularios estándar de reconciliación de la medicación cumplimentados por estudiantes de farmacia durante las entrevistas a pacientes desde abril-2010 a julio-2010. Se registró el número de revisiones realizadas así como la frecuencia de cada tipo de discrepancia. Se definió una discrepancia como cualquier falta de acuerdo entre la lista de medicación en la historia clínica electrónica (HCE) y el régimen reportado por el paciente e incluía cualquier diferencia en dosis o frecuencia de un medicamento, duplicidad del mismo medicamento, medicación discontinuada u omisión de cualquier medicación.

Resultados: Se revisaron un total de 213 formularios estándar de medicación del periodo de 4 meses. Se encontraron un total de 555 discrepancias, incluyendo, medicaciones que ya no se tomaban, medicación que necesitaba ser añadidas a la HCE, medicamentos OTC y plantas medicinales que tenían que añadirse a la HCE, medicación tomadas de modo diferente a lo registrado en la HCE y alergias a medicación que necesitaban actualizarse. Se encontró una media de 2,6 discrepancias por paciente entrevistado. Conclusión: La reconciliación de la medicación iniciada por estudiantes de farmacia en un centro ambulatorio de medicina familiar produjo la resolución de numerosas discrepancias en las listas de medicación de los pacientes. Los farmacéuticos y los estudiantes de farmacia están especialmente entrenados para la toma de historiales de medicación y juegan un papel vital en la 
reconciliación de la medicación en ambiente ambulatorio.

Palabras clave: Reconciliación de Medicamentos. Continuidad de la Atención al Paciente. Historias Clínicas Electrónicas. Estudiantes de Farmacia. Estados Unidos.

\section{INTRODUCTION}

The Joint Commission includes medication reconciliation in ambulatory health care as a national patient safety goal. $^{1}$ The 2011 goal specifically states: "Maintain and communicate accurate patient medication information". ${ }^{1}$ Medication reconciliation is agreement between the medications the patient is taking and the medication list in the medical chart. It is a detailed, accurate and complete account of all medications the patient is taking and exactly how they are taking them. This can be a difficult goal to achieve in outpatient primary care, as patients often visit multiple physicians and purchase numerous over-thecounter (OTC) products for self-treatment. The growing widespread use of electronic health records (EHR) helps with maintaining more accurate medication lists, as everything prescribed in the system is recorded automatically in the medication list. However, most EHRs do not yet communicate with physicians in outside practices, and do not capture OTC products unless they are specifically added to the list. Also, medications may not be discontinued or removed from the list when the course of therapy is completed, a dose is changed, or the medication is no longer being taken. EHRs may give a false sense of accuracy of medication lists, which must be continually verified. Maintaining accurate medication records for each patient can be a time-consuming task requiring ongoing monitoring at each patient appointment.

A study conducted by Bedell and colleagues in a large outpatient practice which used paper medical records identified a large number of medication record discrepancies. ${ }^{2}$ Patient medication bottles and patient reports were prospectively compared to the medical record and discrepancies recorded (any difference between the list of medications in the medical record and what the patient actually took). In 312 patients, a total of 545 discrepancies were found (mean of 1.7 discrepancies per patient). The authors noted that their patient population was well educated and of high economic status, however, $76 \%$ of patients had a discrepancy in their medication list. Over half $(51 \%)$ of discrepancies were from patients taking medications which were not recorded in the medical record. Older age and a higher number of medications were the most significant correlates of discrepancies.

Studies have also demonstrated the importance of medication reconciliation in outpatient settings which use an EHR. In an older study by Wagner and Hogan, a large number of inaccuracies in medication lists were identified in a practice which used a locally developed EHR. ${ }^{3}$ Medication lists in the EHR system were compared with what the patient was taking at 117 patient visits. The physician recorded any discrepancies noted. Patients were taking an average of 5.67 medications. The proportion of medication records that were complete without missing medications was $37 \%$. The most common cause of discrepancies was related to what the patient was actually taking, as they often stop, start or adjust medications on their own. The second most common cause of discrepancies was changes made to medications from outside physicians.

In a study by Orrico, registered nurses conducted medication reconciliation during routine advice-line phone calls when patients called in for acute complaints. ${ }^{4}$ The majority of patients were young (mean age 42, SD 14 years) females (81.2\%) calling in for acute infectious processes. In 85 outpatient calls, 407 medication entries into an electronic medical record were identified. Of those, $233(57.2 \%)$ did not match information obtained by the nurse. An average of 2.7 discrepancies per patient was identified, with the highest percentage being medications no longer taken $(70.4 \%)$. The majority of medication discrepancies were for classes with defined lengths of therapy such as antiinfectives, anti-inflammatories, and analgesics which had not been given an end date. The percentage of medications taken differently than noted on the EHR was only $2.6 \%$ in this study.

In a study by Manley and colleagues at an outpatient hemodialysis center, clinical pharmacists conducted 215 medication interviews in 63 patients over a 5-month period. ${ }^{5}$ Patients typically underwent dialysis 3 times per week and were asked by nurses at each visit if they had sought care elsewhere since the last treatment. Nephrologists also assessed patients 2-3 times/week. During the study period, $60 \%$ of patients had at least one discrepancy identified by the pharmacists. Medication record discrepancies were identified in $30.2 \%$ of the interviews conducted. The mean number of discrepancies per patient was $1.7(\mathrm{SD}=1.3)$ (range 1-7). This included drug not in record, drug has different directions, drug no longer taken by patient, and drug dose changed. The most common discrepancy was drug no longer taken by the patient $(46.0 \%)$, followed by dose discrepancy (34.5\%).

In a study by Ernst and colleagues, clinical pharmacists participating in a prescription-renewal clinic by telephone reviewed the accuracy and completeness of medication orders in an EHR for which a refill was requested. ${ }^{6}$ Medication discrepancies (including taking a medication not listed in the record, not taking a medication listed in the record, or different dosage or directions) were found for $26.3 \%$ of prescription renewal requests. A majority of discrepancies found (58.8\%) were due to prescriptions that the patients were taking which were not recorded in the medical record. However, the EHR had been recently implemented and prescribers were still allowed to hand write or call in prescriptions which may not have been recorded in the EHR. Also, the pharmacist did not review the 
complete medication list, but only the medications which were being inquired about.

In a study by Peyton and colleagues, an intervention to improve the accuracy of nurseconducted medication reconciliation was evaluated. ${ }^{7}$ The study objectives were to determine the baseline accuracy of nurse-conducted medication reconciliation in an outpatient internal medicine clinic, and to assess the effect of pharmacist-provided education interventions to improve the accuracy of medication reconciliation. In the first phase, the nurse completed medication reconciliation forms in the standard manner with each patient. Then the pharmacist reviewed the forms from 90 randomly selected patients and compared them to the patient's 2 previous forms. The pharmacist also spoke with the patient or caregiver to verify the medication list, and called the patient's pharmacy if necessary. After these results were collected, they were shared with the nursing and medical staff. Nursing staff attended a 20 minute educational session conducted by pharmacists on medication reconciliation. Physicians attended a 10 minute educational session. Also, an automated phone call to remind patients of their appointments was modified to encourage them to bring their medications to the appointment.

The second phase was conducted after the educational interventions, and the same process was repeated of medication reconciliation by nurses and pharmacists for 90 patients. In the first phase, only $14.4 \%$ of medication reconciliation forms were correct. In the remaining incorrect forms, 269 errors were found (omitted prescriptions, omitted OTC medications, listed medications that the patient was not taking, incorrect directions, or incorrect strength). After the educational intervention, 18.9\% of medication reconciliation forms were correct, and the incorrect forms contained 220 errors. The mean number of errors per patient decreased from 3.0 $(S D=2.7)$ in the first phase to $2.4(S D=2.3)$ in the second phase $(p=0.14)$. Even though the accuracy of medication improved with the intervention, a large number of errors will still found. This highlights the complexity of medication reconciliation and the special skills that pharmacists bring to the process.

A prospective study by Varkey and colleagues examined the prevalence of medication discrepancies in an outpatient setting and evaluated an intervention to reduce these discrepancies. ${ }^{8}$ The intervention was targeted to patients as well as providers. Patients in the first phase of the study $(n=54)$ were provided usual care and the medication history obtained was documented by the provider in the EHR. In the second phase of the study 50 patients were mailed letters before their appointments to remind them to bring their medication bottles or an updated medication list to their clinic appointment. They were then asked to verify and correct an EHR generated medication list. Providers in this phase were educated on the importance of and how to conduct medication reconciliation, as well as given performance audit results compared to that of their peers on a weekly basis. After each phase, a study nurse obtained the most accurate medication list by telephone or email contact or by reviewing the patient's medication bottles. This list was then compared to the EHR medication list generated by the physician.

In phase 1 , only about $5 \%$ of patients brought in their medications bottles, and a medication list was completely missing for the physician note in $26 \%$ of patients. In phase 2, $52 \%$ of patients brought in their medication bottles and only $6 \%$ of physician notes lacked a medication list. The intervention resulted in an overall decrease in visits with any medication reconciliation discrepancies from $98.2 \%$ in phase 1 to $84 \%$ in phase $2 \quad(p=0.0134)$. The provider's documented medication list improved from only containing $47 \%$ of the medications the patient was taking in phase 1 , to $93 \%$ in phase 2 . The most common error noted in this study was complete omission of a medication from the EHR. This highlights the importance of not only verifying the name, dose, route and frequency of medications already recorded, but also assessing the list for completeness.

In an outpatient study performed in Nigeria by Yusff and colleagues, pharmacist involvement in medication histories for 324 patients significantly increased the frequency and depth of medication information documented. ${ }^{9}$ Documentation of prescription drugs increased from $68.9 \%$ at baseline to $100 \%$ after pharmacist intervention, over-thecounter medication documentation increased from $25.1 \%$ to $96.9 \%$, and herbal drug use documentation increased from $10.7 \%$ to $85.5 \%$ $(p=0.0001$ for all). Even though this study reported an increase in thorough documentation instead of a decrease in discrepancies, it highlights that medication lists in medical records are often incomplete.

Pharmacists play a key role in correcting and reconciling discrepancies in medication records in outpatient settings. They have extensive training and expertise in pharmacotherapy, patient interviewing, assessment of adherence and patient counseling. Medication reconciliation is important in all patient care settings to prevent drug interactions, therapeutic duplication, unnecessary side effects, and other medical errors. Pharmacists working in the outpatient setting can play a role in reconciling medication lists through direct patient interview, examining pill bottles, or calling dispensing pharmacies for verification. The objective of this study was to quantify and describe medication reconciliation efforts by student pharmacists in an outpatient family medicine center.

\section{METHODS}

The practice site is a large family medicine outpatient clinic and staffed by approximately 36 family medicine residents and 8 attending physicians with an average of 2300 patient encounters per month. The patient population is varied and includes obstetric, pediatric and adult patients. The insurance mix consists of $34 \%$ Medicare, 34\% Medicaid, 28\% private insurance 
and 4\% uninsured. In 2006 the practice implemented an EHR and phased out paper charts. The EHR contains a list of current and past medications, which includes all prescriptions written by physicians in the practice. Prescription medications from outside physicians and OTC products can be entered into the list as a medication record. However, there are still many discrepancies when reconciling these lists, including both medications not deleted when discontinued, and medications not added from outside physicians or which the patient has purchased OTC.

The pharmacy student preceptor developed a standardized medication reconciliation form for use in the family medicine center in April of 2010. The form included space for recording medications added to the EHR such as medications prescribed by outside physicians and specialists, OTC and herbal medications added to the EHR which the patient reported, and medications that were discontinued from the EHR (moved to the past medication list). Medications taken differently than prescribed in the EHR could also be recorded, such as a medication prescribed twice a day, but only being taken once a day. The frequency of use of PRN medications could be noted for assessment by the physician. Refills requested by the patient could be recorded, and updates to medication allergies could be noted. Patient counseling performed during the interview could also be documented on the form.

Student pharmacists performed medication histories on patients waiting to see their physician and updated the electronic medication list in the EHR. This included reviewing medication bottles if brought to the appointment and calling pharmacies if necessary. Students concentrated on patients with chronic medications requesting refills with the longest wait time for the physician. No patients were specifically excluded from the reviews, and the same patient could be encountered by a pharmacy student at multiple appointments on different dates. Students then recorded changes made on the standardized medication reconciliation form and left this outside the patient exam room as a summary for the physician of any changes or discrepancies in the medication list. The pharmacy student did not speak directly with each with each physician, but was available for questions. A copy of this form was turned into the pharmacy student preceptor. Student pharmacists performed medication reconciliation approximately 1 or 2 half days per week. Patients not seen by a student pharmacist received usual care, with medication reconciliation performed by the physician.

The researcher received approval from the practice site and the university's institutional review board to conduct the research. A retrospective review was conducted of all standard medication reconciliation forms completed during patient interviews from April 2010 to July 2010. The number of reviews conducted was recorded, along with the frequency of each type of discrepancy. A discrepancy was defined as any lack of agreement between the medication list in the EHR and the patient-reported

\begin{tabular}{|l|c|}
\hline \multicolumn{2}{|l|}{ Table 1. Medication discrepancies recorded $(\mathrm{n}=555)$} \\
\hline Discrepancy & $\mathrm{N}(\%)$ \\
\hline Medications no longer taken & $234(42.1)$ \\
\hline Prescription medications added & $136(24.5)$ \\
\hline OTC and herbal medications added & $107(19.2)$ \\
\hline Medications taken differently than prescribed & $67(12.0)$ \\
\hline Medication allergies updated & $11(1.9)$ \\
\hline
\end{tabular}

regimen. This included differences in dose or frequency of a medication, duplication of the same medication, medication no longer taken or omission of any medication. The frequency of patient counseling was also noted. Descriptive statistics were used to calculate the mean number of discrepancies per patient and the percentages of each type.

\section{RESULTS}

A total of 213 standard medication forms from the 4 month period were reviewed. Six student pharmacists performed patient interviews during this time (2 students over each 5 -week rotation block). A total of 555 discrepancies were found, including medications no longer taken, prescription medications that needed to be added to the EHR, OTC and herbal medications that needed to be added to the EHR, medications taken differently than recorded in the EHR, and medication allergies which needed to be updated (Table 1). There was an average of 2.6 discrepancies found per patient interviewed. Patient counseling was performed and documented by student pharmacists for 47 patients $(22 \%)$ and included discussion of adverse drug reactions, recommendations for OTC products, drug regimen and administration clarification, drug interaction, and lifestyle modification counseling.

\section{DISCUSSION}

Our findings regarding medication record discrepancies are similar to those reported in the literature. We found an average of 2.6 discrepancies per patient reviewed, and the range reported in the articles reviewed was 1.7 to 3.0 per patient. $^{2-5,7}$ Discrepancies related to prescription and OTC medications omitted from the medication list accounted for $43.7 \%$ of the errors we found, which is similar to the results of Bedell, et al and Ernst, et al $\left(51 \%\right.$ and $58.8 \%$, respectively). ${ }^{2,6}$ Medications that had been stopped or discontinued accounted for $42.1 \%$ of the errors we found, while it accounted for $34.5 \%$ in the Manley study and $70.4 \%$ in the Orrico study. ${ }^{4,5}$ Overall, our findings are aligned with previous results when differences in study design are considered. Bedell and colleagues reported that their study included a highly educated population of high economic status, which might explain the lower mean number of discrepancies per patient. ${ }^{2}$ The Orrico study included manly young females with acute infectious processes, and had a high percentage of medications no longer taken. ${ }^{4}$ Manley and colleagues reported a lower percentage of discrepancies than our study, but the hemodialysis patient population had very frequent follow-up. ${ }^{5}$ In the Ernst study, the entire medication list was not reviewed. ${ }^{6}$ 
There are several limitations to this retrospective study. All standardized medication reconciliation forms were handwritten and could have been difficult to read or misinterpreted during data collection. The information gathered during patient interviews was subjective and based solely on patient report. Also, a patient could have multiple resident physicians involved in their care, which could contribute to miscommunication and discrepancies in the medication record. Many errors could have been missed due to inability of patients to remember their medications. Discrepancies in medication lists are not necessarily directly related to patient non-adherence to the prescribed regimen. Patients may be taking all their medications correctly, even though their medication list is not upto-date. Also, a completely accurate medication list does not guarantee patient understanding and adherence. Our study did not separate systembased discrepancies in documentation from patient generated discrepancies (stopping medications, adding OTC medications, not reporting medications from other physicians, or taking medications differently than prescribed). Even when discrepancies were identified, it was often unclear if it was due to lack of documentation by the physician, misunderstanding of directions by the patient, patient non-adherence, or lack of reporting of additional medications by the patient. The time taken for these interventions was not recorded, and the cost effectiveness was not examined. However, in a teaching setting student pharmacists can gain an educational experience while still providing a needed patient care service in this area. The process of medication reconciliation also gives pharmacists and student pharmacists the opportunity to educate patients on medications, adherence and proper administration. This is highlighted by the fact that $22 \%$ of patients in our study received patient counseling by the student pharmacist during the medication history. Pharmacists are familiar with drug names and doses and their extensive training in pharmacotherapy enables them to perform medication reconciliation thoroughly and accurately.

\section{CONCLUSIONS}

Student pharmacist-initiated medication reconciliation in an outpatient family medicine center resulted in the resolution of numerous discrepancies in the medication lists of individual patients. The use of an EHR does not guarantee a decrease in medication discrepancies, and patient interview must be conducted to reconcile medication lists. Each medication on the list must be reviewed for accuracy, and the list must be assessed frequently for completeness. Outpatient medication reconciliation has not been proven to decrease medical errors, but could be speculated to do so through decreasing duplicate therapy, unnecessary therapy, drug interactions, and adverse drug reactions. Pharmacists and student pharmacists are uniquely trained in medication history taking and play a vital role in medication reconciliation in the outpatient setting.

\section{ACKNOWLEDGEMENT}

The author would like to acknowledge Jessica Williams, PharmD, for her assistance with data collection.

\section{CONFLICT OF INTEREST}

No conflicts of interest to report. No funding to report.

\section{References}

1. The Joint Commission. National patient safety goals effective July 1, 2011. Ambulatory Health Care Accreditation Program. Available at: http://www.jointcommission.org/assets/1/6/NPSG_EPs_Scoring_AHC_20110707.pdf (Accessed October 21, 2011).

2. Bedell SE, Jabbour S, Goldberg R, Glaser H, Gobble S, Young-Xu Y, Graboys TB, Ravid S. Discrepancies in the use of medications: their extent and predictors in an outpatient practice. Arch Intern Med. 2000;160(14):2129-2131.

3. Wagner MM, Hogan WR. The accuracy of medication data in an outpatient electronic medical record. J Am Med Inform Assoc. 1996;3(3):234-244.

4. Orrico KB. Sources and types of discrepancies between electronic medical records and actual outpatient medication use. J Manag Care Pharm. 2008;14(7):626-631.

5. Manley HJ, Drayer DK, McClaran M, Bender W, Muther RS. Drug record discrepancies in an outpatient electronic medical record: frequency, type, and potential impact on patient care at a hemodialysis center. Pharmacotherapy. 2003;23(2):231-239.

6. Ernst ME, Brown GL, Klepser TB, Kelly MW. Medication discrepancies in an outpatient electronic medical record. Am J Health Syst Pharm 2001;58(21):2072-2075.

7. Peyton L, Ramser K, Hamann G, Patel D, Kuhl D, Sprabery L, Steinhauer B. Evaluation of medication reconciliation in an ambulatory setting before and after pharmacist intervention. J Am Pharm Assoc. 2010;50(4):490-495.

8. Varkey P, Cunningham J, Bisping S. Improving medication reconciliation in the outpatient setting. Jt Comm J Qual Patient Saf. 2007;33(5):286-292.

9. Yusff KB, Tayo F, Aina BA. Pharmacists' participation in the documentation of medication history in a developing setting: An exploratory assessment with new criteria. Pharm Pract (Internet). 2010;8(2):139-145. 